\title{
Research and the Principle Technique of Intelligent Warehouse System based on RFID and Theory of Data Center
}

\author{
Xuesong Wang ${ }^{1}$, \\ ${ }^{1}$ FoShan Polytechnic, \\ FoShan, Guangdong,528137
}

\begin{abstract}
In this paper, we conduct research on the principle technique of intelligent warehouse system based on RFID and theory of data center. Warehouse management and accurate positioning is a very important link in the whole management process, in order to ensure timely and accurate stock, inventory control and shipment and accurate tracking. Platform provides Internet, wireless networks and other communications excuse, facilitate customer more information related services anytime and anywhere. The RFID combined system could enhance and enlarge the efficiency of the current method. In the future, we will focus on the data analysis and optimization part to modify the method.
\end{abstract}

Keywords: Data Center; RFID; Intelligent Warehouse System; Structure Optimization.

\section{Introduction}

In the past decade, the change in the global economy has significantly redefined the way enterprises are operated. One of the major changes is that the core activity of warehousing in supply chain is no longer confined to keeping a large amount of stock. With the concern and support of the Internet of things industry in China increased significantly, the Internet of things has been the use of a new generation of IT technology in all walks of life, the Internet of things application in intelligent transportation, logistics management, environmental protection and public security, intelligent household and other fields. In logistics management, intelligent storage system can greatly reduce the labor force,

\author{
Guangzhan Feng ${ }^{2}$ \\ ${ }^{2}$ Foshan Huijia science and technology CO.,Ltd
}

improve the efficiency of the operation speed and storage, reduce logistics cost, with the effective combination of supply chain management system, with the help of information technology will be closely united just to suppliers, manufacturers, customers, effectively reduce inventory risk. In this paper, through the establishment of the Internet of things RFID technology combined with intelligent warehouse system of wireless network technology, combined with the enterprise ERP system effective to record and track the product, in the case of every link of enterprise internal logistics, help enterprise logistics management of inventory products inbound, outbound, mobile, inventory, picking operations such as a comprehensive control and management, product batch control, loading and unloading and dynamic inventory, fast and effective use of warehouse storage space, increase the warehouse storage capacity. Warehouse management system is a real-time computer software system, it can according to the logistics operation rules and algorithms, the information, resources, behavior, inventory and distribution operation optimization to maximize the meet the requirements of effective output and precise management. Based on real-time inventory visibility and support the working flow of warehouse, warehouse management system can efficiently organize personnel, space and equipment receiving, storage, picking and shipping and organize delivery of raw materials and components to the production enterprise, carrying finished products to the hands of wholesalers, distributors and end users [1-2].

Therefore, to apply the advancement of RFID technique to more applications, we conduct 
related research on the principle technique of intelligent warehouse system based on RFID and theory of data center in this paper. Warehouse management and accurate positioning is a very important link in the whole management process, in order to ensure timely and accurate stock, inventory control and shipment, and accurate tracking. Platform provides Internet, wireless networks and other communications excuse, facilitate customer more information related services anytime and anywhere. At the same time, combined with the enterprise system, it could record and tracking of the products in the enterprise internal logistics each link. In warehousing logistics center information system as the core, it will usually use the enterprise internal LAN directly connected network technology and leave with the Internet, wireless network interface and in the place where is not convenient wiring, generally uses the wireless LAN technology [3-4]. In the following figure one, we visually describe the general organization of the intelligent ware house.

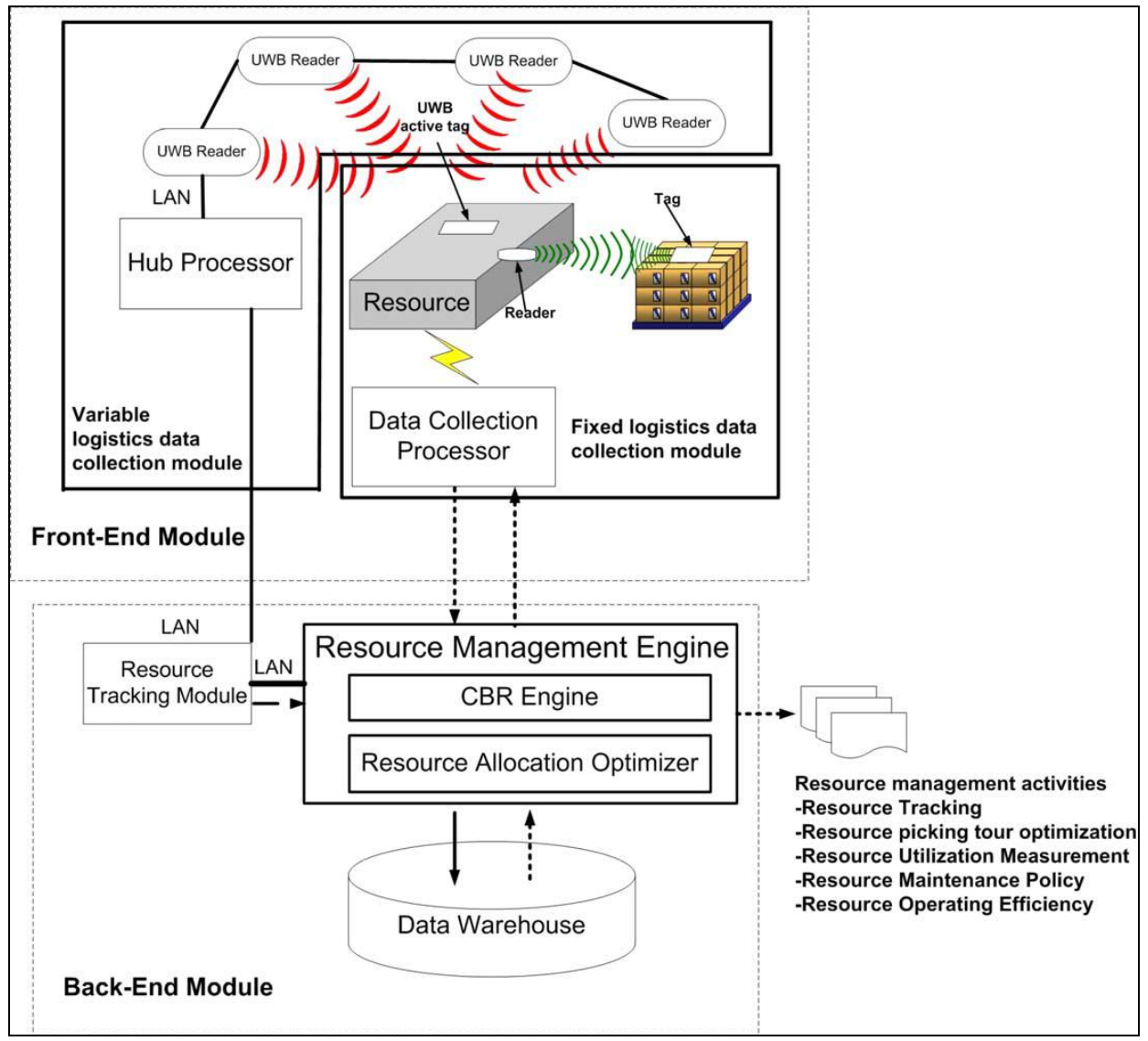

Fig. 1The General Organization of the Intelligent Warehouse

\section{The Proposed Methodology}

The Principles of RFID Technique. Radio Frequency Identification (RFID) is the next generation wireless communication technology applicable to various areas. Warehousing application in our country at present most IOT perception technology is the RFID technology, in some advanced warehousing distribution center, RFID tags and intelligent wireless radio frequency (RF) handset has more extensive application. This is because, the RFID technology and the tray system, closed loop application in warehousing and distribution 
center, can effectively reduce the cost. In addition, the intelligent handheld chosen terminal based on RFID technology, can improve the picking efficiency and speed. In some advanced manufacturing, warehousing and distribution system, automatic conveyor sorting system also often use laser and infrared technology such as perception, positioning and count, for full automatic quick sorting. In addition, in order to make the warehousing homework do visual, video surveillance to the warehouse to part of the storage system uses a video monitoring system of perception which will be achieved good effect.

At present, can achieve the whole process of intelligent control and management of the logistics is not much, also only stay in the Internet of things and logistics information to automatic recognition, automatic perception, automatic positioning, process tracing, online tracking, online scheduling application level in general. In expert systems integration and information sharing, data mining, network optimization, intelligent scheduling and line automatic adjustment management there are great gap between the applications of intelligent management technology. Part in enterprise logistics system, logistics system can also be combined with seamless enterprise production management system, intelligent operation; Part of the intelligent and automation of logistics center can be fully automated and intelligent logistics operation. The biggest trend of modern logistics is networked and intelligent. In modern manufacturing enterprise, storage and distribution center is often and the integration of enterprise production system, storage system as part of the production system, in the enterprise production management plays a very important role.

RFID is a non-contact automatic identification technology, it through radio frequency signal automatically identify target objects and access to relevant data, identify work without manual intervention, it can work in all kinds of bad environment. RFID technology can identify the high-speed movement of objects and identify multiple tags at the same time, the operation is convenient. The development of the Internet of things for the application of RFID in warehousing brought the good development opportunity. With the development of the Internet of things technology, in the field of storage, the application of RFID will gradually expand to wider areas and traces the logistics system integration and product intelligence with greater benefits.

The Principle of Data Center Theory. With the aid of perception technology integration application, in the special goods warehouse monitoring system, can be used in environmental monitoring, warehouse to meet environmental parameters such as temperature, humidity, air composition of distributed monitoring demand, realize the intelligent storage environment. Application of wireless sensor network (WSN) in dangerous goods logistics management, real time monitoring and a state of containers of dangerous goods, once more than alert value can timely alarm, thus for dangerous goods logistics process of tracking, monitoring, management, etc. In the cold storage logistics system, can monitor all the frozen products in the environment of temperature and humidity, regulating the temperature and humidity in time, ensure the quality of products. In the following formula one, we illustrate the expression of the data processing method.

$$
\operatorname{MinT}_{m}^{s}=\sum_{s=0}^{q} \sum_{t=1}^{q} d_{s t} z_{s t}
$$

If storage IOT truly, and can be the basis of the implementation in greater warehousing logistics network storage system of the Internet of things and the intelligent, make things in the big system of storage and Internet of things has certain intelligence, let the things of the logistics knows where to, shall be deposited into what position, etc., under the idea of establishing logistics system of Internet of things, and it is very different from the original system of Internet of things. 


$$
\sum_{i=1}^{n} w_{i} \times \operatorname{sim}\left(f_{i}, f_{r}\right) / \sum_{i=1}^{n} w_{i}
$$

The process of the development of the Internet of things is not a mutation, but the automatically from information extraction, information integration, local area network, intelligence service and control to the entire network of local system integration process of gradually deepened. Modern storage system internal items not only complex, different forms, performance, and the process is complex, both the storage, and mobile, both the sorting, there is also a combination. Therefore to warehousing logistics center as the core of intelligence, often using the intelligent pile technology with automatic control technology, intelligent robot palletizing technology, intelligent information management technology, mobile computing technology and data mining technology, etc. The development of the Internet of things technology and there are growing concerns on the properties of physical items, will promote the integrated application of warehousing of various kinds of perception technology which is shown in the formula two.

The Combination of RFID and Warehouse System. Based on RFID automatic identification technology in combination with the wireless network technology of modern intelligent warehouse management system is effective to improve the quality and efficiency of enterprise logistics management, reduce the inventory cost and improve enterprise's market competitiveness. Ago, the Internet of things technology is limited to the application in a separate warehouse distribution center internal network, still is independent, local intelligent storage system. With the help of the Internet of things technology, the independent intelligent warehouse system connected to the Internet, break the information island, realize each other, form the real storage and Internet of things, is based on intelligent storage produce new change, it will be a revolution of storage information. Through the Internet, making the material information throughout the supply chain up and down, to achieve seamless at the ends of the supply and marketing industry enterprises. Improve the real-time, accuracy and effectiveness of logistics distribution, to implement low cost, on-demand supply model of logistics warehousing. Through the Internet of things technology will link up with all items related to the supply chain upstream and downstream enterprises, forming an end-to-end smart supply chain logistics service process. The figure 2 shows the organization of the system. 


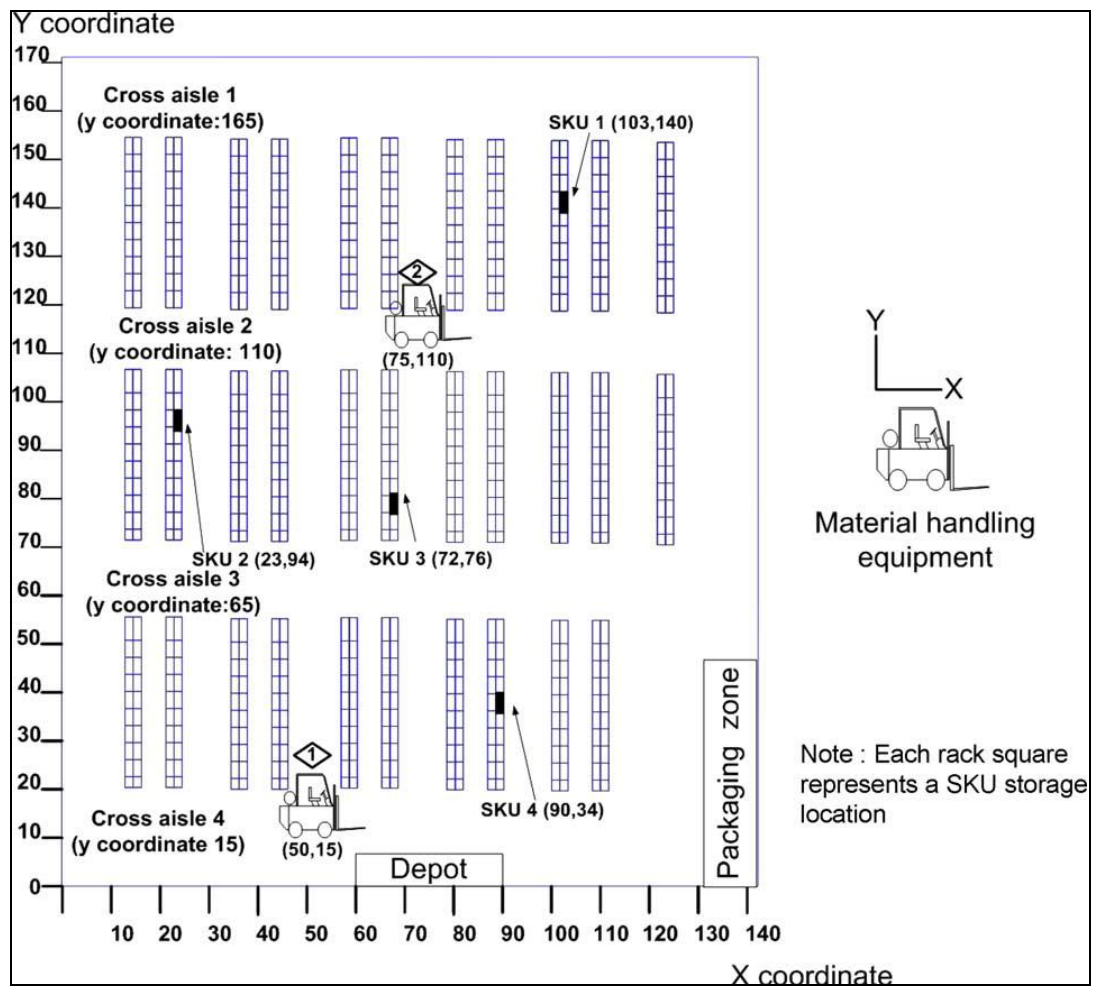

Fig. 2The Organization and Layout of the Designed System

\section{Conclusion}

This paper conducts theoretical and numerical research on the principle technique of intelligent warehouse system based on RFID and theory of data center in this paper. With the help of the Internet of things technology, the independent intelligent warehouse system connected to the Internet. Warehouse management system is a real-time computer software system, it can according to the logistics operation rules and algorithms, the information, resources, behavior, inventory and distribution operation optimization to maximize the meet the requirements of effective output and precise management. The application of the RFID combined system will enhance the current pattern of the system. In the future, we will conduct more research to polish the current methodology.

\section{References}

[1] Jun-hui, Z., \& Quan, G. (2014). Design and implementation of intelligent warehouse management system based on rfid. Electronic Design Engineering.

[2] Xiao-xiao, B., Min-zhi, H., Gong-ting, Y., Ping, C., \& College, J. (2014). Design and development of intelligent warehouse management system based on rfid. Computer Programming Skills \& Maintenance.

[3] Yang, L., Ye, M., Yang, L., \& Ye, M. (2014). The design and development of intelligent warehouse management system based on .net and internet of things. lemcs-14.

[4] Wang, G., Shuchao, L., Feng, G., Xianghua, R., Shen, L., \& University, Q. N. (2014). Design and implementation of small and medium intelligent warehouse management system based on html5. 